\title{
The relation between zero-time pretransplant deceased donor renal biopsy and kidney transplant survival
}

This article was published in the following Dove Medical Press journal:

Research and Reports in Urology

\author{
Mahmoud Tavakkoli' \\ Masoud Yousefi ${ }^{2}$ \\ Reza Mahdavi \\ Mahmoud Reza Kalantari ${ }^{3}$ \\ Amin Mirsani ${ }^{2}$ \\ Amin Korooji ${ }^{2}$ \\ 'Kidney Transplantation Complications \\ Research Center, Mashhad University \\ of Medical Sciences, Mashhad, Iran; \\ ${ }^{2}$ Department of Urology, Faculty \\ of Medicine, Mashhad University \\ of Medical Sciences, Mashhad, Iran; \\ ${ }^{3}$ Department of Pathology, Faculty \\ of Medicine, Mashhad University of \\ Medical Sciences, Mashhad, Iran
}

\begin{abstract}
Introduction: There are several investigations about preimplantation biopsy results in alive donors. However, assessment of the biopsies in deceased donors' kidney and its correlation with patient survival is limited. In this study, we evaluated the correlation between zero-time pretransplant kidney biopsy and survival of kidney in deceased donors.

Patients and methods: This was a cohort study conducted at Montaserieh Hospital, Mashhad, between January 2016 and December 2017. We included all brain dead patients who were referred to Montaserieh transplantation center. After vascular anastomosis of kidneys in recipient patients, in the operation room, and de-clumping of vessels, biopsies were taken from upper pole of donated kidney. Blocks of biopsies were evaluated by expert pathologists and then reported We followed patients for 1 year and compared the pathologic findings and renal survival in them. Results: The mean age of deceased donors was $32.32 \pm 1.49$ years and that of the recipient patients was $36.33 \pm 1.27$ years. Thirty-eight recipient patients $(45.2 \%)$ were female and 46 were male $(54.8 \%)$. The most pathologic pattern in our study was grade I separation, followed by blebs, dilatation, and loss of attenuation. We showed that most of the transplantations were safe after 1-year follow-up (85.7\%) without any complications. We observed thrombosis in two cases $(2.4 \%)$ and rejection of transplantation in ten patients $(11.9 \%)$. Cox regression analysis showed that end-stage renal disease grade $(\mathrm{HR}=3.84,95 \% \mathrm{CI}=2.315-6.348 ; P<0.0001)$ and gender of the deceased donors $(\mathrm{HR}=0.34,95 \% \mathrm{CI}=0.145-0.797 ; P=0.013)$ were related to graft survival rate Conclusion: Only cast feature in pathologic exam was related to graft survival, which is a marker of tissue ischemia. There was no significant correlation between other histological findings and graft survival.
\end{abstract}

Keywords: survival rate, transplant, renal biopsy, graft outcome, kidney, deceased donors

\section{Introduction}

Kidney transplantation is now the best choice for the survival of patients with endstage renal disease (ESRD). ${ }^{1}$ This therapy exhibits a good cost/benefit ratio and can elevate the survival and quality of life of patients with ESRD. It has been estimated that the number of cases with chronic kidney disease and requiring a kidney transplant is increasing yearly by $8 \%$ in the USA. ${ }^{2}$ Iran is a pioneer in the Middle East region in performing kidney transplant for patients. ${ }^{3}$ In the past, the majority of renal transplantations in Iran were from living donors, yet recently deceased donation of organs has been increasing. ${ }^{4}$ This is due to an international acceptance for extension of using organs, which was not accepted until recently. ${ }^{5,6}$ However, a crucial factor to be considered before kidney transplantation from a deceased donor is kidney biopsy of the donated kidney to assess the functionality and efficiency of the transplanted
Correspondence: Masoud Yousef Department of Urology, Ghaem Hospital, Shariati Square, Ebn-e-Sina Street, Post box 1339, 9137913316, Mashhad, Iran Tel +989156129891 Email drmyousefil@yahoo.com 
kidney. This is also important in predicting the mid-term and long-term outcomes of transplantation in the patient. ${ }^{7,8}$ The function of the donors' kidney after transplantation can be evaluated by measuring serum creatinine. ${ }^{9,10}$ The early outcomes of transplantation during the first months of operation were evaluated by measuring serum creatinine levels. ${ }^{11}$ The presence of pathological changes in live donors' kidneys has been shown by previous studies. ${ }^{12}$

Preimplantation biopsies play a major role in defining structural integrity and the functional reserve of kidney specimens. ${ }^{13,14}$ Different algorithms based on histological parameters have been proposed to evaluate kidneys from donors with expanded criteria. ${ }^{15}$ In biopsies performed according to standard protocols, it is known that glomerulosclerosis, interstitial fibrosis, and arteriosclerosis are associated with an inferior kidney function in the long term. ${ }^{16,17}$ The criteria used to decide whether kidneys from donors are suitable for kidney transplantation are not univocal. Useful parameters to consider when making transplant-related decisions are the history of the donor, their renal function, the anatomical appearance of the kidneys at ultrasonography and macroscopic evaluation, and the histological findings of the preimplantation biopsy. ${ }^{18}$ Histological scores as an index of severity of renal lesions can be a good predictor for future graft outcome. ${ }^{19,20}$ Although there are several investigations about preimplantation biopsy results in alive donors, the assessment of biopsies in deceased donors' kidneys and its correlation with patient survival is limited. This study evaluated the correlation between zero-time pretransplant kidney biopsy and survival of kidneys in deceased donors.

\section{Patients and methods}

This was a cohort study performed at Montaserieh Hospital, Mashhad, between January 2016 and December 2017. The research included all brain dead patients, who were referred to Montaserieh transplantation center.

\section{Eligibility criteria}

All the candidates with verified brain death were included for transplantation. The study excluded patients who did not have suitable kidneys for transplantation, those without consent from their parents or protector to participate in the study, and those in whom both kidneys were donated en-bloc to one receptor patient.

\section{Study design}

Informed consent was obtained from the patients' parents or protectors for recruitment in the study. This was also done for receptor patients. After vascular anastomosis of kidneys in recipient patients, in the operation room, and de-clumping of vessels, biopsies were taken from the upper pole of donated kidneys. Blocks of biopsies were evaluated by an expert pathologist. The patients were followed for 1 year and correlation between their pathologic findings and renal survival was analyzed.

\section{Pathologic evaluation}

The evaluated liver specimens were wedge biopsies with 2-4 H\&E stained sections available for review. Periodic acid-Schiff and trichrome stains were performed for all cases. All specimens were assessed for glomerulosclerosis, hypoxia, and arteriosclerosis. The degree of acute tubular necrosis in donated kidneys was categorized as grades: mild $(10 \%-25 \%)$, moderate $(25 \%-50 \%)$, or severe $(>50 \%)$. The function of donated kidneys was evaluated by glomerular filtration rate (GFR) and with Modification of Diet in Renal Disease Study equation on the first day, first week, first month, and after 1 year. We used the parameters like urine volume, serum creatinine, and GFR $<15 \%$ to demonstrate the loss of kidney function. The primary end point of the study was 1-year graft survival.

\section{Statistics}

This research used descriptive tests for reporting continuous variables, including mean or median. Categorical data were presented as frequencies and percentages. Graft survival was computed using Kaplan-Meier method. Proportions were compared using the chi-squared test. Univariate and multivariate analyses were conducted using the log-rank test. Variables that were significant at the $P<0.05$ univariate level were included in the multivariate analysis. $P$-values $<0.05$ were considered significant. All analyses were performed using the SPSS software, version 16.0 (SPSS Institute, Inc., Chicago, IL, USA).

\section{Ethics statement}

This study was approved by the Editorial Board of Urology of Mashhad University of Medical Sciences with an ethical code of IR.MUMS.fm.REC.1393.764. We obtained written informed consent from all legal attendants of each subject.

\section{Results}

The mean age of deceased donors was $32.32 \pm 1.49$ years and that of recipients was $36.33 \pm 1.27$ years. Thirty-eight recipients $(45.2 \%)$ were female and 46 were male $(54.8 \%)$. Other demographic data are listed in Table 1. 
Table I Baseline and demographic data of deceased donors and recipient patients

\begin{tabular}{|c|c|c|c|}
\hline \multicolumn{2}{|c|}{ Characteristics } & \multirow[b]{2}{*}{ Female } & \multirow[b]{2}{*}{$24,28.5$} \\
\hline \multirow[t]{11}{*}{ Deceased } & \multirow[t]{2}{*}{ Gender (n, \%) } & & \\
\hline & & Male & $60,71.5$ \\
\hline & \multirow[t]{2}{*}{ Kidney side $(\mathrm{n}, \%)$} & Left & $50,59.5$ \\
\hline & & Right & $34,40.5$ \\
\hline & Age (mean $\pm S D)$, years & \multicolumn{2}{|c|}{$32.32 \pm 1.49$} \\
\hline & Cause of brain death $(n, \%)$ & \multicolumn{2}{|c|}{$\begin{array}{l}\text { Brain trauma }(38,70) \text {; brain tumor }(2,4) \text {; poisoning }(4,7) \text {; CVA }(6, \text { II }) \text {; seizure }(2 \\
8) \text {; encephalopathy }(2,4)\end{array}$} \\
\hline & Serum creatinine (mean $\pm \mathrm{SD}$ ), $\mathrm{mg} / \mathrm{dL}$ & \multicolumn{2}{|c|}{$0.99 \pm 0.28(0.5-1.7)$} \\
\hline & Urinary output (mean $\pm \mathrm{SD}$ ), $\mathrm{mL} /$ day & \multicolumn{2}{|c|}{$2,387.50 \pm 44 I .29(I, 800-3,200)$} \\
\hline & Right kidney size (mean $\pm \mathrm{SD}$ ), $\mathrm{mm}$ & \multicolumn{2}{|c|}{$110.75 \pm 12.01(70-120)$} \\
\hline & Left kidney size (mean $\pm S D)$, $\mathrm{mm}$ & \multicolumn{2}{|c|}{$111.10 \pm 12.20(70-120)$} \\
\hline & Vascular resistance index (mean \pm SD) & \multicolumn{2}{|c|}{$0.65 \pm 0.05(0.5 I-0.75)$} \\
\hline \multirow[t]{4}{*}{ Recipient } & Gender (n, \%) & Female & $38,45.2$ \\
\hline & & Male & $46,54.8$ \\
\hline & Age $($ mean $\pm S D)$, years & \multicolumn{2}{|c|}{$36.33 \pm 1.27(14-65)$} \\
\hline & Cause of ESRD $(n, \%)$ & \multicolumn{2}{|c|}{$\begin{array}{l}\text { Hypertension }(22,26.2) \text {; DM }(2,2.4) \text {; hypertension+ DM }(12,14.3) \text {; nephrotic } \\
\text { syndrome (I0, II.9); PCKD }(2,2.4) \text {; HUS }(2,2.4) \text {; Alport syndrome }(2,2.4) \text {; VUR } \\
(6,7.1) \text {; PSGN }(2,2.4) \text {; kidney stone }(2,2.4) \text {; idiopathic }(22,26.2)\end{array}$} \\
\hline
\end{tabular}

Abbreviations: ESRD, end-stage renal disease; DM, diabetes mellitus; CVA, cerebrovascular accident; PCKD, polycystic kidney disease; HUS, hemolytic-uremic syndrome; VUR, vesicoureteral reflux; PSGN, poststreptococcal glomerulonephritis.

The study showed that most of the transplantations were safe after 1-year follow-up (85.7\%) without any complications. We observed thrombosis in two cases $(2.4 \%)$ and rejection of transplant in ten patients (11.9\%).

The results showed that $85.71 \%$ of recipients had a complete kidney survival after the 12-month follow-up. Table 2 shows the pathologic characteristics of preimplant biopsy of deceased kidneys, by their grading score, in rejected and survived groups.

There was no significant correlation between pathological indexes and kidney survival $(P>0.05)$, except cast $(P=0.03)$. Table 3 shows the findings of posttransplantation outcomes in the patients.

Data of the two groups (survived or not) are listed in Table 4.

Cox regression analysis showed that ESRD grade (HR $=3.84,95 \% \mathrm{CI}=2.315-6.348 ; P<0.0001)$ and gender of deceased donors $(\mathrm{HR}=0.34,95 \% \mathrm{CI}=0.145-0.797 ; P=0.013$ ) were related to graft survival rate (Table 5). Figure 1 indicates the pattern of survival according to these variables. It was demonstrated that the risk of graft survival failure was 3.84 times more in higher grades of ESRD and 0.34 times more in the female gender. There was no significant relationship between survival prognosis and existence of pathological variables $(P>0.05)$. The median GFR between the two groups was significantly different (renal survival group, mean rank: 7.5; rejected group, mean rank: $49.5 ; P<0.001)$.

\section{Discussion}

This study was an analysis of biopsies from brain dead donors with expanded criteria for recipients. All of the biopsy specimens were obtained in regards to clinical protocols. ${ }^{21}$ Various investigations have addressed different issues related to preimplantation kidney biopsies and recommended a set of histopathologic parameters to be evaluated based on their predictive value for graft outcome. ${ }^{22-25}$ Histopathologic scoring systems and evaluations were suggested to assist decision-making by transplant teams, regarding organ acceptability for transplantation. However, there are limited studies on deceased biopsies, and in this study, we evaluated them histopathologically, and followed the patients for 1 year and examined the kidney survival.

The major findings were that after 1-year follow-up, graft survival was observed in $85.7 \%$ of the cases, thrombosis in two cases $(2.4 \%)$, and rejection of transplantation in ten patients (11.9\%). Some studies suggested that biopsies from donors are not beneficial; however, this is probably related to the lack of true definition and crude survival findings in these studies. ${ }^{26}$ The current study only reported the determinants of histopathologic findings and found no significant relationship between variables and survival rate. We showed that only cast in the samples was significantly different between survived and rejected cases. Naderi et al showed that glomerulosclerosis in donated kidneys was not associated with graft rejection. Their results demonstrated that 
Table 2 Pathologic characteristics of preimplant biopsy of the deceased kidneys

\begin{tabular}{|c|c|c|c|c|c|c|c|c|c|c|c|}
\hline \multirow{2}{*}{\multicolumn{2}{|c|}{ Characteristics }} & \multicolumn{2}{|c|}{$\begin{array}{l}\text { Kidney survival } \\
\text { (n, \%) }\end{array}$} & \multirow{3}{*}{\begin{tabular}{|l|}
$\begin{array}{l}\text { Total } \\
(n, \%)\end{array}$ \\
12,100
\end{tabular}} & \multirow{3}{*}{\begin{tabular}{|l|}
$P$-value \\
0.12 \\
\end{tabular}} & \multirow{2}{*}{\multicolumn{2}{|c|}{ Characteristics }} & \multicolumn{2}{|c|}{$\begin{array}{l}\text { Kidney survival } \\
(n, \%)\end{array}$} & \multirow{3}{*}{$\begin{array}{l}\begin{array}{l}\text { Total } \\
(n, \%)\end{array} \\
8,100\end{array}$} & \multirow{3}{*}{\begin{tabular}{|l|}
$P$-value \\
0.72 \\
\end{tabular}} \\
\hline & & \multirow{2}{*}{\begin{tabular}{|l|} 
No \\
0 \\
\end{tabular}} & \multirow{2}{*}{$\begin{array}{l}\text { Yes } \\
12,100\end{array}$} & & & & & \multirow{2}{*}{\begin{tabular}{|l|} 
No \\
0 \\
\end{tabular}} & \multirow{2}{*}{\begin{tabular}{|l|} 
Yes \\
8,100 \\
\end{tabular}} & & \\
\hline Coagulative & Normal & & & & & Blebs and shedding & Normal & & & & \\
\hline \multirow[t]{3}{*}{ necrosis } & Mild & $4,10.5$ & $34,89.5$ & 38,100 & & of proximal tubular & Mild & 6,20 & 24,80 & 30,100 & \\
\hline & Moderate & $4,22.2$ & $14,77.8$ & 18,100 & & epithelium & Moderate & $4,14.3$ & $24,85.7$ & 28,100 & \\
\hline & Severe & $6,37.5$ & $10,62.5$ & 16,100 & & & \begin{tabular}{|l|} 
Severe \\
\end{tabular} & $4,22.2$ & $14,77.8$ & 18,100 & \\
\hline \multirow[t]{4}{*}{ Swelling } & \begin{tabular}{|l|} 
Normal \\
\end{tabular} & $10,19.2$ & \begin{tabular}{|l|}
$42,80.8$ \\
\end{tabular} & 52,100 & \multirow[t]{4}{*}{0.83} & \multirow{4}{*}{$\begin{array}{l}\text { Separation and } \\
\text { detachment }\end{array}$} & Normal & $2,16.7$ & $10,83.3$ & 12,100 & \multirow[t]{4}{*}{0.45} \\
\hline & Mild & $2,11.1$ & $16,88.9$ & 18,100 & & & Mild & $10,21.7$ & \begin{tabular}{|l|}
$36,78.3$ \\
\end{tabular} & 46,100 & \\
\hline & Moderate & $2,14.3$ & $12,85.7$ & 14,100 & & & Moderate & 2,10 & 18,90 & 20,100 & \\
\hline & Severe & - & - & - & & & Severe & 0 & 6,100 & 6,100 & \\
\hline \multirow{4}{*}{$\begin{array}{l}\text { Loss of } \\
\text { attenuation }\end{array}$} & Normal & 0 & 10,100 & 10,100 & \multirow[t]{4}{*}{0.32} & \multirow[t]{4}{*}{ Thinning } & Normal & $6,14.3$ & $36,85.7$ & 42,100 & \multirow[t]{4}{*}{0.25} \\
\hline & Mild & $4,14.3$ & $24,85.7$ & 28,100 & & & Mild & 2,10 & 18,90 & 20,100 & \\
\hline & \begin{tabular}{|l|} 
Moderate \\
\end{tabular} & 8,20 & 32,80 & 40,100 & & & \begin{tabular}{|l|} 
Moderate \\
\end{tabular} & 6,30 & 14,70 & 20,100 & \\
\hline & Severe & $2,33.3$ & $4,66.7$ & 6,100 & & & \begin{tabular}{|l|} 
Severe \\
\end{tabular} & 0 & 2,100 & 2,100 & \\
\hline \multirow[t]{3}{*}{ Dilatation } & \begin{tabular}{|l|} 
Normal \\
\end{tabular} & $8,14.8$ & \begin{tabular}{|l|}
$46,85.2$ \\
\end{tabular} & 54,100 & \multirow[t]{3}{*}{0.47} & \multirow[t]{3}{*}{ Interstitial edema } & Normal & $12,14.6$ & \begin{tabular}{|l|}
$70,85.4$ \\
\end{tabular} & 82,100 & \multirow[t]{3}{*}{0.026} \\
\hline & Mild & $6,21.4$ & \begin{tabular}{|l|}
$22,78.6$ \\
\end{tabular} & 28,100 & & & \begin{tabular}{|l|} 
Mild \\
\end{tabular} & 2,100 & 0 & 2,100 & \\
\hline & Moderate & 0 & 2,100 & 2,100 & & & Moderate & - & - & - & \\
\hline \multirow[t]{4}{*}{ Casts } & Normal & $8,11.8$ & $60,88.2$ & 68,100 & \multirow[t]{4}{*}{0.03} & \multirow[t]{4}{*}{ Sloughing } & Normal & $14,18.4$ & $62,81.6$ & 76,100 & \multirow[t]{4}{*}{0.39} \\
\hline & Mild & $4,33.3$ & $8,66.7$ & 12,100 & & & Mild & 0 & 6,100 & 6,100 & \\
\hline & \begin{tabular}{|l|} 
Moderate \\
\end{tabular} & 0 & 2,100 & 2,100 & & & \begin{tabular}{|l|} 
Moderate \\
\end{tabular} & 0 & 2,100 & 2,100 & \\
\hline & Severe & 2,100 & 0 & 2,100 & & & Severe & - & - & - & \\
\hline \multirow{2}{*}{$\begin{array}{l}\text { Peri-tubular } \\
\text { scan }\end{array}$} & Normal & 12,15 & 68,85 & 80,100 & \multirow[t]{2}{*}{0.067} & Apoptosis & Normal & $14,17.5$ & $66,82.5$ & 80,100 & 0.475 \\
\hline & Mild & 2,50 & 2,50 & 4,100 & & & Mild & 0 & 4,100 & 4,100 & \\
\hline Proximalization & Normal & $14,17.1$ & $68,82.9$ & 82,100 & 0.693 & Focal calcification & Normal & $14,17.5$ & $66,82.5$ & 80,100 & 0.475 \\
\hline & Mild & 0 & 2,100 & 2,100 & & & Mild & 0 & 4,100 & 4,100 & \\
\hline
\end{tabular}

Table 3 Findings of posttransplantation outcomes in patients

\begin{tabular}{|c|c|c|c|c|}
\hline \multirow{2}{*}{\multicolumn{2}{|c|}{$\begin{array}{l}\text { Variables } \\
\text { Complication }\end{array}$}} & \multicolumn{2}{|c|}{ Kidney survival } & \multirow[t]{2}{*}{$P$-value } \\
\hline & & Yes & No & \\
\hline \multicolumn{2}{|l|}{ None (n, \%) } & $70,97.20$ & $2,2.8$ & \multirow[t]{3}{*}{$<0.001$} \\
\hline \multicolumn{2}{|l|}{ Reject $(n, \%)$} & $2,2.8$ & $8,66.7$ & \\
\hline \multicolumn{2}{|c|}{ Thrombosis (n, \%) } & 0 & $2,16.7$ & \\
\hline \multirow{5}{*}{$\begin{array}{l}\text { Grade of ESRD } \\
(\mathrm{N}, \%)\end{array}$} & $\mathrm{I}$ & 2,100 & 0 & \multirow[t]{5}{*}{$<0.001$} \\
\hline & II & 26,100 & 0 & \\
\hline & III & 42,100 & 0 & \\
\hline & IV & 0 & 6,100 & \\
\hline & $\mathrm{V}$ & 0 & 8,100 & \\
\hline
\end{tabular}

Abbreviation: ESRD, end-stage renal disease.

no allograft dysfunction was observed in $55(95 \%)$ patients during the first month, 51 (88\%) in 6 months, and 53 (91\%) during the first year. They reported that survival rate after deceased transplant was $89 \%$, whereas that of living-donor transplants was $99 \% .{ }^{27}$ Mossad et $\mathrm{al}^{28}$ designed a study with 63 renal transplant children, weighing $25 \mathrm{~kg}$ or less at the time of renal transplantation. They received a living donor renal allotransplant and were retrospectively evaluated for survival, graft survival, as well as physical growth. Their results demonstrated that patient and graft survival rate at 1 year was $98.4 \% .{ }^{28}$ Chamienia et $\mathrm{al}^{29}$ found delayed graft function in three cases and an acute rejection episode in four subjects among the 29 cases. One-year patient and graft survival rates were both $100 \%$ (98\% and $83 \%$ for deceased donor kidney transplantation). Five-year patient and graft survival rates were $100 \%$ and $89.6 \%$, respectively, compared with $83 \%$ and $69 \%$ in deceased donor kidney transplantation. ${ }^{29}$ Rezaei et al ${ }^{30}$ revealed that graft survival rates in 1 year were $85.6 \%$ and $97.4 \%$, in 3 years were $77.2 \%$ and $92.3 \%$, and in 10 years were $33.3 \%$ and $60.6 \%$ in living unrelated donors and living related donors, respectively. ${ }^{30}$ Ghaffari et al demonstrated that in 39 cases, who had undergone kidney transplant from deceased donors, 1-year patient survival rate was $89.7 \%{ }^{31}$ Hashiani et al ${ }^{32}$ reported this survival rate as 93.7\% (32 cases) and Yazdani et al reported this as $92.3 \%{ }^{33}$

The rate of survival in the current study for deceased transplant in comparison with other studies was relatively poor. This can be related to population differences and demographic baseline characteristics and larger number of cases that were evaluated. Cecka et al reported the survival rate as $89 \%$ for deceased samples and $95 \%$ for living ones. ${ }^{34}$ Kaitelidou et al reported the survival rate from deceased samples in 38 cases after 1 year as $95 \%$ for patients and $85 \%$ for grafts. ${ }^{35}$ The rate of graft survival after 1 year is an important factor, which influences overall survival in transplantation. Therefore, suitable reported function in the current study can 
Table 4 Differences in laboratory variables between the two groups

\begin{tabular}{|c|c|c|c|}
\hline \multirow[t]{2}{*}{ Variables } & \multicolumn{2}{|l|}{ Kidney survival } & \multirow[t]{2}{*}{$P$-value } \\
\hline & Yes & No & \\
\hline Deceased serum creatinine (mean \pm SD) & $1.00 \pm 0.26$ & $1.01 \pm 0.20$ & 0.91 \\
\hline Age of deceased (mean $\pm S D$ ), years & $32.75 \pm 12.97$ & $37.83 \pm 17.69$ & 0.40 \\
\hline Age of recipient (mean $\pm S D$ ), years & $34.91 \pm 12.39$ & $44.83 \pm 12.36$ & 0.07 \\
\hline Seventh day creatinine (mean $\pm \mathrm{SD}$ ), $\mathrm{mg} / \mathrm{dL}$ & $1.47 \pm 0.30$ & $3.8 I \pm 2.50$ & 0.05 \\
\hline 30th day creatinine (mean $\pm \mathrm{SD}$ ), $\mathrm{mg} / \mathrm{dL}$ & $1.35 \pm 0.30$ & $3.48 \pm 2.20$ & 0.04 \\
\hline I-year creatinine $($ mean $\pm S D), \mathrm{mg} / \mathrm{dL}$ & $1.38 \pm 0.30$ & $5.08 \pm 2.20$ & $<0.001$ \\
\hline Recipient gender (n, \%) & Male $(34,47.3)$, female $(38,52.7)$ & Male $(12,100)$, female $(0)$ & 0.01 \\
\hline Vascular resistance index (mean $\pm S D)$ & $0.66 \pm 0.04$ & $0.65 \pm 0.07$ & 0.87 \\
\hline Urinary output of deceased (mean \pm SD) & $2,418.10 \pm 408.85$ & $2,366.70 \pm 467.61$ & 0.78 \\
\hline Urinary output of recipient (mean \pm SD) & $3,777.80 \pm 84 \mid .46$ & $1,308.30 \pm I, 951.51$ & 0.02 \\
\hline
\end{tabular}

Table 5 Multivariate analysis by the Cox regression model

\begin{tabular}{|c|c|c|c|c|c|c|}
\hline \multirow[t]{2}{*}{ Characteristics } & \multirow[t]{2}{*}{ SE } & \multirow[t]{2}{*}{ Wald } & \multirow[t]{2}{*}{ P-value } & \multirow[t]{2}{*}{ HR } & \multicolumn{2}{|c|}{$95.0 \% \mathrm{Cl}$} \\
\hline & & & & & Lower & Upper \\
\hline Coagulative necrosis & -0.183 & 0.458 & 0.690 & 0.833 & 0.339 & 2.045 \\
\hline Blebs and shedding of proximal tubular epithelium & 0.012 & 0.564 & 0.983 & 1.012 & 0.335 & 3.057 \\
\hline Swelling & 0.229 & 0.295 & 0.437 & 1.257 & 0.706 & 2.239 \\
\hline Separation and detachment & -0.036 & 0.646 & 0.955 & 0.965 & 0.272 & 3.423 \\
\hline Loss of attenuation & 0.240 & 0.418 & 0.566 & 1.271 & 0.560 & 2.885 \\
\hline Thinning & 0.405 & 0.413 & \begin{tabular}{|l|}
0.327 \\
\end{tabular} & 1.500 & 0.667 & 3.370 \\
\hline Dilation & -1.036 & 0.510 & 0.042 & 0.355 & 0.131 & 0.965 \\
\hline Cast & .212 & 0.382 & 0.579 & 1.236 & 0.584 & 2.616 \\
\hline Sloughing & -0.672 & 0.573 & 0.241 & 0.511 & 0.166 & 1.570 \\
\hline Grade of ESRD & 1.344 & 0.257 & $<0.000$ I & 3.834 & 2.315 & 6.348 \\
\hline Deceased age & -0.006 & 0.013 & 0.673 & 0.994 & 0.969 & 1.021 \\
\hline Deceased gender & -1.080 & 0.435 & 0.013 & 0.340 & 0.145 & 0.797 \\
\hline Deceased serum creatinine & -0.464 & \begin{tabular}{|l|l|}
0.563 \\
\end{tabular} & 0.410 & 0.629 & 0.208 & 1.897 \\
\hline Deceased urinary output & 0.000 & 0.000 & 0.510 & 1.000 & 0.999 & 1.001 \\
\hline Deceased left kidney size & -0.037 & 0.026 & 0.146 & 0.963 & 0.916 & 1.013 \\
\hline Deceased right kidney size & 0.018 & 0.029 & 0.530 & 1.018 & 0.962 & 1.078 \\
\hline Recipient age, years & 0.000 & 0.014 & 0.980 & 1.000 & 0.974 & 1.027 \\
\hline Recipient gender & 0.355 & 0.283 & 0.209 & 1.427 & 0.820 & 2.483 \\
\hline
\end{tabular}

Note: Bold text $=P<0.05$.

Abbreviations: ESRD, end-stage renal disease; SE, standard error.

indicate the long-term survival of patients. One of the reasons for relatively high survival rate in the current study can be due to the source of transplant being cases with brain death.

Cox regression analysis showed that ESRD grade ( $\mathrm{HR}=3.84,95 \% \mathrm{CI}=2.315-6.348 ; P<0.0001)$ and gender of deceased donors (HR $=0.34,95 \%$ CI $=0.145-0.797$; $P=0.013$ ) had independently been related to graft survival rate. Mossad et $\mathrm{al}^{28}$ demonstrated significant risk factors for growth retardation postrenal transplant, which included older age at time of transplant $(P=0.019)$, female gender $(P=0.010)$, retarded growth at time of transplant $(P=0.011)$, incidence of chronic rejection $(P=0.012)$, higher steroid cumulative dose $(P=0.013)$, and graft dysfunction $(P=0.009) .{ }^{28}$ Rezaei et al ${ }^{30}$ showed that in the Cox model, four factors, including the presence of surgical or other complications, known primary disease, and donor-recipient relationship, had a significant association with patient survival, and seven factors, including the presence of surgical complications, known primary disease, donor-recipient relationship, gender, weight, same side transplanted kidney, and donor's age, had significant relationship with graft survival. ${ }^{30}$ Pegas et al's ${ }^{2}$ multivariate model found an association with the presence of arteriosclerosis, glomerulosclerosis, acute rejection, and delayed graft function.

The current study showed that the 30-day mean serum creatinine after transplant in patients with suitable renal 

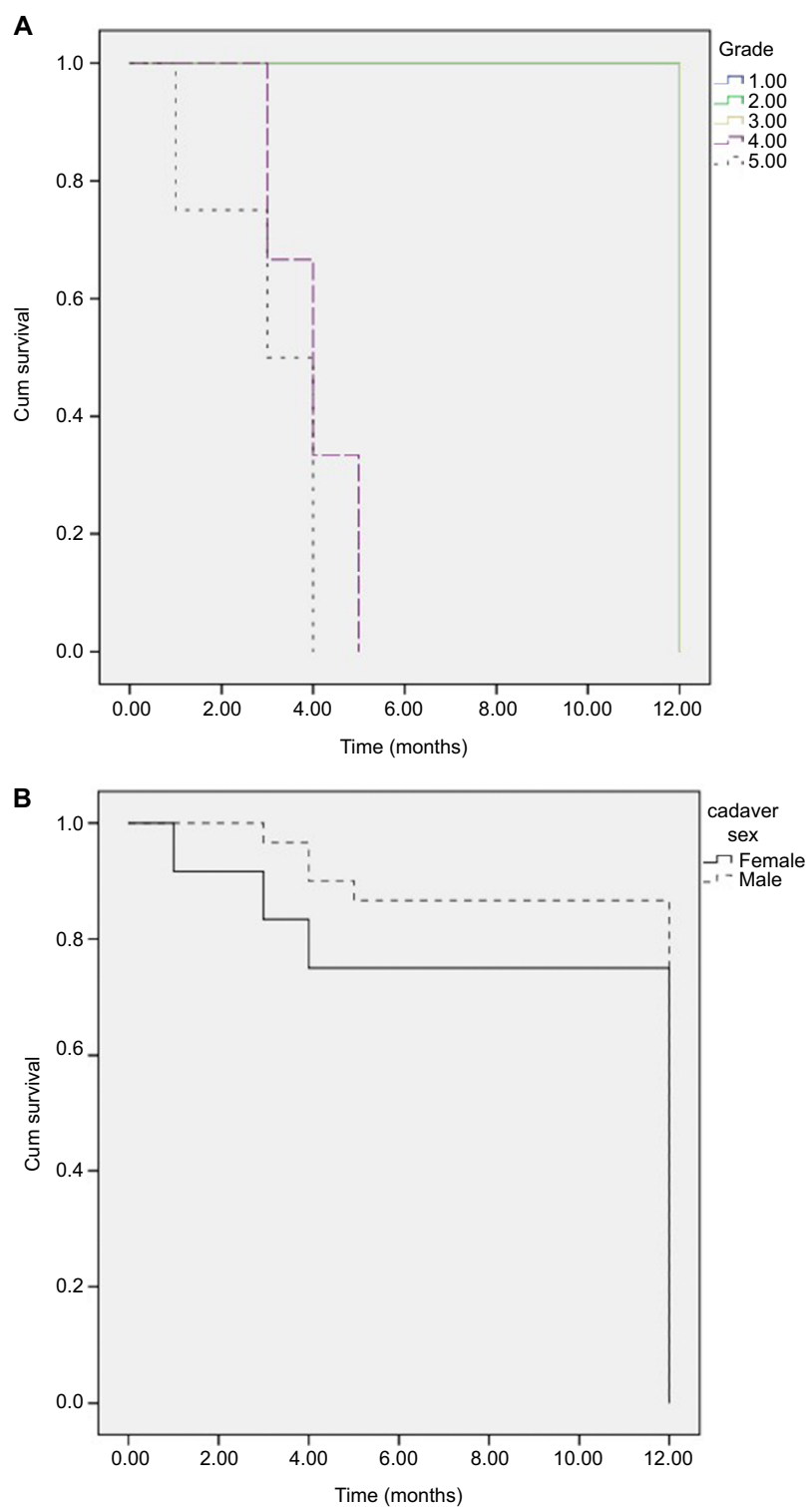

Figure I Survival rate of cases according to ESRD grade $(\mathbf{A})$ and gender of deceased donor (B).

Abbreviation: ESRD, end-stage renal disease.

function was $1.35 \pm 0.30 \mathrm{mg} / \mathrm{dL}$ and was significantly different from patients with rejected graft $(3.48 \pm 2.2 \mathrm{mg} / \mathrm{dL})$. Chamienia et al demonstrated that the mean serum creatinine levels at $1,6,12$, and 60 months were $1.59 \pm 0.4,1.51 \pm 0.3$, $1.51 \pm 0.4$, and $1.49 \pm 0.3 \mathrm{mg} / \mathrm{dL}$, respectively. ${ }^{29}$ The importance of transplanted kidneys during the long-term follow-up is determined by percentage of creatinine. It was reported that if serum creatinine after 6 months was equal or lower than $1.5 \mathrm{mg} / \mathrm{dL}$, the rate of survival would be $80 \%{ }^{36}$

There was no significant relationship between pathologic indexes and kidney survival $(P>0.05)$, except cast $(P=0.03)$. Pegas et $\mathrm{l}^{2}$ evaluated the prevalence of chronic alterations in preimplant biopsies of kidney grafts and the association of findings with graft function and survival in 1-year posttransplant in 110 biopsies, including live donors, ideal deceased donors, and those with expanded criteria. The score was computed according to criteria suggested by Remuzzi. They showed that no statistical difference was found in the survival of donors, stratified according to Remuzzi criteria, and that the GFR was significantly associated with total scores in the groups with mild and moderate alterations, and alone in the compartments of kidney. ${ }^{2}$ Taheri et al used the Banff scoring system in their study and evaluated pathological lesions in rejected transplanted kidneys. They showed that the most frequent rejections were tubular atrophy, interstitial fibrosis grades 2 and 3, and acute rejection with grades IA and IIB, respectively. ${ }^{37}$ Ratnakar et al ${ }^{38}$ in a 10 -year retrospective study on renal transplant biopsies evaluated histological changes, according to Banff's working classification of renal allograft pathology. They showed that out of 26 cases, 10 belonged to hyper-acute and acute forms, whereas 11 could be categorized to chronic sclerosing allograft nephropathy. In the remaining five, the graft pathology was unrelated to the rejection process. Presence of tubular atrophy and interstitial matrix increase were considered useful parameters for assessing severity in cases with chronic allograft nephropathy. ${ }^{38}$ In Escofet et al's study, ${ }^{39}$ patients with over $20 \%$ glomerulosclerosis had worse kidney function in 1 year. Bajwa et al, ${ }^{40}$ analyzing 12,129 preimplantation kidney biopsies, noted that presence of more than 5\% glomerulosclerosis was associated with a more unfavorable outcome. On the other hand, Cockfield et al, ${ }^{22}$ in a study with 730 biopsies, did not show an independent association of glomerulosclerosis with the prognosis. Sulikowski et al showed that in 121 patients, there was no significant association between renal function and arterial hyalinization, fibrosis, inflammatory infiltration, and tubular atrophy. ${ }^{41}$ Most investigations showed that there was no significant relationship between pathological changes and graft survival. Despite these results, the current study showed that cast in pathological assessment is related to graft survival and can be an important factor and the degree of these changes should be considered for patient survival prediction.

\section{Conclusion}

The current study showed that graft survival was $85.71 \%$, which was comparable with results of other regions. Overall, there was no significant relationship between histological findings and graft survival. However, cast in pathological exam was related to graft survival. The most common pathologic pattern in the current study was grade I separation, followed by blebs, dilatation, and loss of attenuation. We demonstrated that ESRD grade and 
gender of deceased donors were independently related to graft survival rate. The study limitation was the shortterm follow-up and patients will be resumed for long-term follow-up evaluations.

\section{Disclosure}

The authors report no conflicts of interest in this work.

\section{References}

1. Wolfe RA, Ashby VB, Milford EL, et al. Comparison of mortality in all patients on dialysis, patients on dialysis awaiting transplantation, and recipients of a first cadaveric transplant. $N$ Engl J Med. 1999;341(23): 1725-1730.

2. Pêgas KL, Michel K, Garcia VD, et al. Histopathological analysis of pre-implantation donor kidney biopsies: association with graft survival and function in one year post-transplantation. J Bras Nefrol. 2014;36(2):186-193.

3. Daar, Abdallah S. Organ donation - world experience; the Middle East. In Transplantation proceedings, 1991;23(5):2505-2507.

4. Yazdani M, Izadpanahi MH, Gharaati MR, Tadayonn F. Deceased kidney transplantation: five years experience at a single center. Transpl Proc. 2007;39(4):904-906.

5. Port FK, Bragg-Gresham JL, Metzger RA, et al. Donor characteristics associated with reduced graft survival: an approach to expanding the pool of kidney donors1. Transplantation. 2002;74(9):1281-1286.

6. Delmonico FL, Burdick JF. Maximizing the success of transplantation with kidneys from older donors. $N$ Engl J Med. 2006;354(4): 411-413.

7. Randhawa P. Role of donor kidney biopsies in renal transplantation. Transplantation. 2001;71(10):1361-1365.

8. Bosmans JL, Woestenburg A, Ysebaert DK, et al. Fibrous intimal thickening at implantation as a risk factor for the outcome of cadaveric renal allografts. Transplantation. 2000;69(11):2388-2394.

9. First MR. Renal function as a predictor of long-term graft survival in renal transplant patients. Nephrol Dial Transplant. 2003;18(Suppl 1): i3-i6.

10. Fitzsimmons WE, Thompson D, Hariharan S, Van Veldhuisen P. Serum creatinine as a surrogate endpoint for graft loss in kidney transplantation. Am J Transpl Suppl. 2002;2:272.

11. Tejani A, Stablein DM, Ho PL. Calculated creatinine clearance (CCC) as the most promising candidate surrogate end point for clinical trials. Am J Transpl Suppl. 2002;2:256.

12. Mancilla E, Avila-Casado C, Uribe-Uribe N, et al. Time-zero renal biopsy in living kidney transplantation: a valuable opportunity to correlate predonation clinical data with histological abnormalities. Transplantation. 2008;86(12):1684-1688.

13. Lopes JA, Moreso F, Riera L, et al. Evaluation of pre-implantation kidney biopsies: comparison of Banff criteria to a morphometric approach. Kidney Int. 2005;67(4):1595-1600.

14. Snoeijs MG, Buurman WA, Christiaans MH, et al. Histological assessment of preimplantation biopsies may improve selection of kidneys from old donors after cardiac death. Am J Transpl. 2008;8(9): 1844-1851.

15. Solez K, Colvin RB, Racusen LC, et al. Banff 07 classification of renal allograft pathology: updates and future directions. Am J Transpl. 2008;8(4):753-760.

16. Kayler LK, Mohanka R, Basu A, Shapiro R, Randhawa PS. Correlation of histologic findings on preimplant biopsy with kidney graft survival. Transpl Int. 2008;21(9):892-898.

17. Serón D, Carrera M, Grinñó JM, et al. Relationship between donor renal interstitial surface and post-transplant function. Nephrol Dial Transpl. 1993;8(6):539-543.

18. Faenza A, Sestigliani E, Zambianchi L, Ridolfi L, editors. Utilization of suboptimal kidney donors. Transpl Proc. 2004;36(3):485-487.
19. Randhawa PS, Minervini MI, Lombardero M, et al. Biopsy of marginal donor kidneys: correlation of histologic findings with graft dysfunction. Transplantation. 2000;69(7):1352-1357.

20. El-Husseini A, Sabry A, Zahran A, Shoker A. Can donor implantation renal biopsy predict long-term renal allograft outcome? Am J Nephrol. 2007;27(2):144-151.

21. Vincenti F, Charpentier B, Vanrenterghem Y, et al. A phase III study of Belatacept-based immunosuppression regimens versus cyclosporine in renal transplant recipients (BENEFIT study). Am J Transplant. 2010;10(3):535-546.

22. Cockfield SM, Moore RB, Todd G, Solez K, Gourishankar S. The prognostic utility of deceased donor implantation biopsy in determining function and graft survival after kidney transplantation. Transplantation. 2010;89(5):559-566.

23. Duman, S., S. Özbek, S. Şen, S et al. Is "zero-hour" biopsy of the transplanted kidney risky?. In Transplantation proceedings, 2004;36(1): $137-138$.

24. Ekser B, Rigotti P. Transplantation: Can a single criterion determine the use of ECD kidneys? Nat Rev Nephrol. 2010;6(2):68-70.

25. Randhawa P. Role of donor kidney biopsies in renal transplantation. Transplantation. 2001;71(10):1361-1365.

26. Ratner L, Joseph V, Zibari G, et al, editors. Transplantation of Kidneys from Hypertensive Deceasedic Donors. Transplantation Proceedings. 1995.

27. Naderi GH, Sotoudeh M, Mehraban D, Nategh S. Reliability of zero time pre-transplant live donor renal biopsies in predicting the graft outcome. Int J Organ Transpl Med. 2014;5(2):71-77.

28. Mosaad AM, Hamdy AF, Hassan NM, et al. Evaluation of growth in low-body-weight kidney transplant Egyptian children: 25-year experience. J Nephrol. 2012;25(3):363-372.

29. Chamienia A, Dębska-Ślizień A, Rutkowski B, Zadrożny D, Moszkowska G. 11-year single-center experience in living-donor kidney transplantation in Poland. Transplant Proc. 2011;43(8):2911-2913.

30. Rezaei M, Kazemnejad A, Bardideh A, Mahmoudi M. Factors affecting survival in kidney recipients at Kermanshah. Urol J. 2004;1(3):180-187.

31. Ghafari A, Afshari AT, Makhdoomi K, et al., editors. Deceased Renal Transplantation: A Single-Center Experience. Transplantation Proceedings. Elsevier; 2009.

32. Hashiani AA, Rajaeefard A, Hasanzadeh J, et al. Ten-year graft survival of deceased-donor kidney transplantation: a single-center experience. Renal Failure. 2010;32(4):440-447.

33. Yazdani M, Izadpanahi MH, Gharaati MR, Tadayonn Feditors, editors. Cadaveric kidney transplantation: five years experience at a single center. Transplant Proc. 2007;39(4):904-906Elsevier.

34. Cecka JM, Terasaki PI. The UNOS scientific renal transplant registry. Clin Transplant. 1993:1-18.

35. Kaitelidou D, Ziroyanis PN, Maniadakis N, Liaropoulos LL. Economic evaluation of hemodialysis: implications for technology assessment in Greece. Int J Technol Assessment Health Care. 2005;21(1):40-46.

36. First MR. Renal function as a predictor of long-term graft survival in renal transplant patients. Nephrol Dial Transplant. 2003;18(90001):i3-i6.

37. Taheri D, Talebi a, Salem V. The relative frequency of via biopsy diagnosed renal diseases in patients with renal transplantation. J Isfahan Med School. 2011;28(114).

38. Ratnakar K, George S, Datta B, et al. Renal transplant pathology: bahrain experience. Saudi J Kidney Dis Transplant. 2002;13(1):71.

39. Escofet X, Osman H, Griffiths DF, Woydag S, Adam Jurewicz W. The presence of glomerular sclerosis at time zero has a significant impact on function after cadaveric renal transplantation. Transplantation. 2003;75(3):344-346.

40. Bajwa M, Cho YW, Pham PT, et al. Donor biopsy and kidney transplant outcomes: an analysis using the organ procurement and transplantation Network/United network for organ sharing (OPTN/UNOS) database. Transplantation. 2007;84(11):1399-1405.

41. Sulikowski T, Tejchman K, Ziętek Z, et al., editors. Histopathologic Evaluation of Pretransplantation Biopsy As A Factor Influencing Graft Function After Kidney Transplantation in 3-year Observation. Transplantation Proceedings. Elsevier; 2010. 
Research and Reports in Urology is an international, peer-reviewed, open access journal publishing original research, reports, editorials, reviews and commentaries on all aspects of adult and pediatric urology in the clinic and laboratory including the following topics: Pathology, pathophysiology of urological disease; Investigation and treatment of urological disease; Pharmacology of drugs used for the treatment of urological disease. The manuscript management system is completely online and includes a very quick and fair peer-review system, which is all easy to use. Visit http://www.dovepress.com/testimonials.php to read real quotes from published authors

Submit your manuscript here: https://www.dovepress.com/research-and-reports-in-urology-journal 